\section{THE PATHOLOGY OF SYDENHAM'S CHOREA.}

BY J. GODWIN GREENFIELD, M.D. EDIN., M.R.C.P. LOND.,

PATHOLOGIST TO THE NATIONAL HOSIITAL FOR TUE PARALYSED AND EI'ILET'TIC;

AND

J. M. WOLFSOHN, M.D.,

ASBOCIATE PROFESSOR OF MEDICINE, LELAND STANFORD JUNIOR UNIVERSITY, GAIIFORNIA, U.S.A.

THE nature and cause of the manifestations of chorea minor have been the object of investigation for many years among clinicians, pathologists, and more recently among bacteriologists : later advances in neuro-pathological and bacteriological methods, together with many clinical reports of cases, have assisted the evolution of the modern conception of disease. A brief historical retrospect of some of the older theories of chorea may be of interest.

\section{Historical Retrospect.}

As early as 1840 Todd $^{1}$ and others were already teaching the relationship between chorea and the rheumatic diathesis, but no causal connexion between chorea and valvular heart disease complicating rheumatic fever was considered until somewhat later. Dr. James A. Wilson (1843) attributed the phenomena of chorea not to the nervous system but to a morbid blood affecting the muscular system. To this explanation Todd objected, claiming "that since the seat of active nutrition was in the mesocephale, a state of the blood, prejudiced by the rheumatic diathesis acting upon the mesocephale, was responsible for the manifestations of chorea." Todd's conception was further elaborated by Kirkes ${ }^{2}$ and Hughlings Jackson, ${ }^{3}$ who expounded the "embolic theory" of chorea. Their conclusions were influenced by the preponderating number of their choreic patients who suffered from valvular heart disease. These authors were among the first to connect cardiac vegetations with chorea. Jackson located the seat of the lesions in chorea "in the nerve tissue forming the convolutions near the corpus striatum, this part of the brain being supplied by branches of the middle cerebral artery." He maintained that if the ganglia were destroyed paralysis resulted, whilst if only an impairment or perversion of their function occurred, chorea resulted. This embolic theory of Kirkes and Jackson gained widespread acceptance, and was supported by Russell Reynolds in his text-book on the diseases of the nervous system.

In $1868 \mathrm{Ogle}^{\mathrm{i}}$ reported 16 fatal cases of chorea. The cardiac conditions in his cases confirmed Jackson's findings. Ogle, however, opposed the embolic theory, and rather believed that "the predisposing cause of chorea was an altered condition of the blood." Broadbent $(1869),{ }^{5}$ in a series of articles, supported Jackson's views in many particulars. He agreed that "the most frequent and most important cause of chorea was no doubt embolism of the minute vessels of the sensori-motor ganglia," but insisted that "other cases occur which are inconsistent with this condition." He regarded chorea as " a symptom rather than a disease, which cannot be referred to any single pathological condition, but as symptomatic only of the seat of the disease, and arises out of the function of the part delirium of the sensori-motor ganglia, which may be caused not only by embolism, but by hyperæmia of the vessels not blocked, or by a morbid condition of the blood." He therefore laid stress on the seat of the disturbance with its altered function rather than on the nature of the lesion.

In 1869 Bastian $^{6}$ first offered his thrombasis theory of chorea, and in 1877 stated it in the following terms :"Chorea was effected by an altered and often anæmic state of the blood as its predisposing cause, in an individual of certain age and nervous temperament. The initiation in such an individual of a disturbed nutrition in the corpora striata and adjacent parts of the brain tended to issue in what may be called a subacute inflammation of these centres, often characterised in part by the production of multiple minute thromboses." Maragliano (1899)? elaborated Bastian's theory by considering chorea the result of a toxic infectious process. He believed that "chorea is in a certain number of cases a complication in a special localisation of an infectious disease, either septic or toxic." "This has since been called the "toxi-infectious theory" of chorea.

For a decade previous to this time investigators were working on the bacteriological status of chorea, and in 1899 Wassermann, Westphal and Malkoff ${ }^{8}$ isolated a diplococcus from the pericardial and cerebro-spinal fluids of a child dead of rheumatic pericarditis and chorea. Dana (1894), ${ }^{9}$ Poynton and Paine (1901-3), 10 l3atten and Walker (1903), i among others, isolated a similar coccus in their cases. Poynton and Paine named this coccus the Diplococcus rheumaticus. Some investigators were able to recover a staphylococcus, and others Streplococcus viridans, from the blood of their choreic patients.

The monumental work of Poynton, Paine, and Holmes confirmed the work of previous investigators, and crystallised our present conception of rheumatism and chorea. They not only recovered $D$. rheumaticus from the blood, cerebro-spinal fluid, and even from the brain and its membranes, but they were able to produce irregular movements, carditis, and arthritis experinentally in rabbits by intravenous injections of the diplococci obtained from their fatal cases, and, further, to demonstrate the diplococci in the brain and pia mater of the rabbit that had shown irregular movements. Their conclusions, drawn from evidence accumulated for years from the clinical, pathological, and bacteriological aspects of the disease, were that the great majority of cases of chorea are rheumatic in nature, and that rheumatic chorea is the outcome of an infection of the brain and its meninges with the Diplococcus rheumaticus; that the pathological changes in chorea consisted of vascular and inflammatory lesions, the chief of which were hyperæmia, and the presence of thrombosed vessels in the central nervous system and meninges. They saw no emboli in the sections studied. In the acute stages slight local lesions consisting of hæmorrhage, thrombosis, and perivascular round-cell infiltration and exudation were found external to the blood capillaries, while in the more chronic cases there was also a perivascular fibrosis. Chromatolysis was present in varying degrees in the nerve cells throughout the cortex and basal ganglia. The pons, medulla, and cerebellum were little affected except for vascular congestion, and roundcelled infiltration of the sheaths of the nerves issuing from them.

Delcourt and Sand $(1908)^{12}$ found in their 16 fatal cases of chorea extreme hyperæmia in the nerve centres, occasionally extending to the formation of hæmorrhages, and perivascular infiltration, alterations in the nerve cells, especially in the cortex and basal ganglia, with secondary neuronophagia, and cellular and fibrillary gliosis. The most intense lesions were seen to be in the basal ganglia, while those in the cortex, cerebellum, and meninges were less prominent. The changes in the bulb, spinal cord, and spinal root ganglia were very slight.

In 1910 Guizzetti and Camisa ${ }^{13}$ published an account of the pathological changes in two fatal cases of chorea, both of which were complicated with endocarditis. They concluded that "the pathological lesion in chorea minor was a disseminated encephalitis involving the pia mater, and associated with numerous ischæmic foci in the brain resulting from embolism of the cerebral arteries; these changes were constantly accompanied by slight changes in the nerve cells of the cerebrum, especially in the cortex, and are certainly due to attack by a special form of organism by way of the blood-vessels."

As recently as 1920 Harvier and Levaditi ${ }^{14}$ concluded "that certain acute febrile choreas are determined by the virus of epidemic encephalitis, although not all the acute febrile choreas were caused by this agent; that it is possible that Sydenham's chorea in children is in certain cases determined by the virus of epidemic encephalitis." The lesions found in their cases were predominantly mesencephalic, and were less prominent in the spinal cord. They consisted histologically of (1) much hyperæmia, and (2) small roundcelled perivascular infiltration. No neuronophagia noticed.

Among the most recent studies has been that of Pierre Marie and Trétiakoff. ${ }^{15}$ These authors found constant and identical lesions in the nerve centres of fatal cases of acute chorea-viz., a " large extent of inflammation, most of which is at the level of the basal ganglia with equally severe inflammation of the cerebral cortex. As one reaches the mesencephalon the morbid process is rapidly attenuated." They conclude that the pathology of chorea " is apparently above all an irritative process characterised by an intense hyperæmia and much infiltration of the tissues by leucocytic elements and by neuroglial and connective tissue proliferation."

\section{A Fatal Case of Acute Chorea.}

It may be concluded from a study of the above that there is still much to be written about the pathology of the disease. It is therefore useful to record still further observations and studies of fatal cases. With this in view the following case of acute chorea, with death supervening on the tenth day, is detailed.

The patient, A. M. (female), aged 7 years 7 months, was admitted to the Hospital for Sick Children, Great Ormondstreet, under Dr. Robert Hutchison, on April 27th, 1920 , with a history of "St. Vitus's dance" of one week's duration. 
Family History.-Father, aged 50 , suffered from sciatica and Iumbago. Mother, aged 13, had had rheumatic fever three times as a child. One brother, aged 14, had had muscular rheumatism in the leg for seven months. Another brother and three sisters were alive and well. The family of eight lived in a five-roomed house which was damp.

Personal History. - A full-time child, normal birth and development, measles at 5 years, whooping-cough and German measles at 6 years.

Present Illness. Up to the onset of the disease the child had been apparently well and attending school. St. Vitus' dance appeared suddenly on April 20th. When handed a piece of bread the child dropped it and kept "twitting about." When she tried to put the bread into her mouth she jerked her arm up to her face and over her shoulder. She also kept moving her legs about and could not keep still. This condition gradually became worse, and for fou days prior to admission to hospital she had been unable to feed herself. The right side of her body had become very weak.

Condition on Admission. - The patient was a dark-haired, well-developed, poorly nourished girl of $7 \frac{1}{2}$ years. She was quite intelligent and could carry out commands, but did not speak. The skin and mucous membranes were pale. The respirations were 80 per minute. There was some dyspnca with expiratory grunting and use of the accessory respiratory muscles. The child showed occasional choreic movements of her hands, but otherwise lay quite still in bed. With the exception of bossing of the forehead there was no skeletal sign of rickets. A few small rheumatic nodules were seen on the elbows, but none on the occiput or knees. The finger-tips were slightly cyanosed and expanded laterally, but not clubbed. The superficial lymphatic glands were not enlarged. The tongue was furred and flabby, and the tonsils much enlarged but not inflamed. Temperature $99^{\circ}$ F., pulse 144 , respiration 80 per minute

Cardio-vascular System.-The præcordia bulged slightly, especially in the fourth and fifth intercostal spaces. The heart-beat was diffuse, being visible in the third, fourth, and fifth spaces, and causing pulsation in the epigastrium. The maximum impulse was felt in the fifth space just inside the nipple line. The area of cardiac dullness reached from outside the right border of the sternum to $1 \mathrm{~cm}$. outside the left nipple line in the fourth intercostal space. The heart rhythm was galloping and the sounds difficult to analyse. No murmurs were detected.

Respiratory System. - The percussion note was impaired in the left interscapular region from the level of the fourth dorsal spine to below the angle of the scapula. In this area the breath sounds were tubular; elsewhere they were harsh. No rhonchi or râles were anywhere heard.

Digestive System.-Normal.

Nervous System.-The eyes reacted to light. The kneejerks were not obtained. The plantar responses were of the flexor type.

On April 29th the temperature was normal, respirations 58 to 68 per minute, pulse 130 . No choreic movements could now be seen. On the 30 th the pulse and temperature remained the same; the patient became steadily weaker, and died on the same day.

Post-mortem Examination.-This was performed six hours after death, and the following notes were taken : Welldeveloped child, length 48 in., weight 41 lb. Trachea and larynx normal; a gland at bifurcation of trachea much enlarged. The pleural and pericardial cavities normal. lungs œedematous throughout, but showed no consolidation. Heart was much enlarged, weight empty $6 \frac{1}{4}$ oz. The right side was considerably dilated. Vegetations were seen on both the mitral and aortic valves, those on the latter being few and small, while those on the mitral valves were large and luxuriant. Cultures made from the heart's blood remained sterile. Smears from the vegetations on the valves showed a few doubtful cocci. The abdominal cavity contained a certain amount of clear fluid. The liver looked pale and fatty and weighed $11 \mathrm{lb} .11 \frac{3}{4} \mathrm{oz}$. The spleen weighed $3 \mathrm{oz}$. right kidney $2 \mathrm{oz}$., left kidney $3 \mathrm{oz}$. The brain on naked-eye observation showed no obvious abnormality.

\section{Detailed Appearance of the Brain.}

The brain was hardened as a whole in formalin, and only some months afterwards was it decided to investigate it by microscopical examination. As a result of the long formalin fixation it was found impossible to get satisfactory staining of the nerve cells by Nissl's method, but hæmatoxylin with eosin or van.Gieson's counter-stain gave satisfactory staining for the examination of the pathological changes. An examination of sections taken from various parts of the brain showed that everywhere above the pons there was evidence of slight encephalitis. This was evidenced by an excess of small round cells within the tissues both in the grey and white matter, by dilatation of blood-vessels, and by neuronophagy of nerve cells in varying degree.

The appearances were very similar to those seen in many cases of encephalitis lethargica, especially in the earlier stages, with the difference that whereas in that disease the nflammatory changes are usually most noticeable in the brain stem, and are more obvious in the grey than the white matter of the brain, in this case they were almost confined to the brain proper and were as great in certain parts of the white matter, such as the internal and external capsules, as in the grey matter. The greatest degree of change was seen in the head of the left caudate nucleus, but the whole of the basal ganglia, cortex, and centrum ovale were affected to some degree. The changes seen may be described under the headings of vascular changes, small-celled infiltration, and changes in the nerve cells.

Vascular Changes.-These were present everywhere in the brain. Many of the cortical vessels had undergone thrombosis, and in many of the larger veins the inner part of the thrombus consisted of red blood corpuscles and fibrin, whereas the outer part was a layer of leucocytes one or two cells deep. In several of the smaller vessels the thrombus consisted almost entirely of leucocytes, both polymorphonuclear and lymphocyte varieties being present. Between these cells there was a small amount of fibrin, but in most cases there was no room between the cells for this to be seen. Such leucocytic plugs were seen in the calcarine fissure (Fig. 1), over the frontal and parietal regions and less frequently in the substance of the brain, especially in the neighbourhood of the anterior perforated space. The walls of the plugged vessels did not show any gross inflammatory changes, but in the neighbourhood there was always a greater degree of small-celled infiltration than was seen elsewhere. Everywhere the blood-vessels were dilated, and the numerous distended capillaries made the brain substance appear unduly vascular. Many of these capillaries showed evidence of proliferation of their endothelial lining, and outside this there were in many places chains of small round cells which appeared to have issued through the capillary walls (Fig. 2).

Small-celled Infiltration.-This type was seen in varying degree all through the brain substance. It was certainly most obvious in the basal ganglia, particularly in the head of the caudate nucleus and the posterior part of the optic thalamus and the tegmentum of the mid-brain (Fig. 3). In these situations it was not uncommon to find groups of 20 or more small cells clustered together in the neighbourhood of a small arteriole or venule. They were not in the perivascular lymphatic space, but in the tissues immediately outside this. In no place could we find so great an accumulation of small cells within the perivascular lymph channels, although in a few vessels one or two cells, or at most a single ring of cells, could be seen in this situation. A very striking appearance was the collection of small cells between the fibres of the internal capsule, especially between the fibres which run across this to link together the various parts of the corpus striatum. In sections of the basal ganglia the bundles of these fibres were picked out by the unusual number of small round cells which they contained, and in many places more cells were seen in these bundles than in the grey matter surrounding them. In the internal capsule, especially in its lower part, the accumulation of small cells was fairly dense, and in relation to some of the large vessels entering from the base of the brain they were so closely packed as almost to suggest a perivascular infiltration. Here again, however, they were not within the perivascular lymph space, but in the brain tissue just outside this. The external capsule was less infiltrated than the internal, but here and there collections of as many as 20 cells were found lying closely packed between the ibres. In the cortex the increase in the number of small cells was less obvious, and in most places amounted to little more than an excessive number of glial-like nuclei. As has been already said, the infiltration was greater in the neighbourhood of vessels which were plugged with leucocytes. Everywhere the subpial layer of glia was respected and showed neither increase in the number of glial nuclei nor small-celled proliferation. In the upper part of the mid-brain, especially in the tegmental region, a slight degree of small-celled infiltration was seen This became progressively less on passing downwards, and in the pons there was practically no alteration from the normal. It was particularly noticeable that no such cellular infiltration was seen among the bundles of the corticopontine and cortico-spinal fibres as was seen in the internal capsule.

As regards the nature of the cells which had infiltrated the brain substance, they appeared to be for the most part small (this which made an There was little or no evidence of glial proliferation, and practically no large forms of glial cells were seen. Callular infiltration was seen in a few places in the pia arachnoid and was nowhere very striking.

Nerve Cell Changes.-As already remarked, it was not possible to obtain satisfactory staining of the Nissl granules but a general idea of the condition of the nerve cells could be got by staining with hæmatoxylin. The alterations in 
Frg. 1.

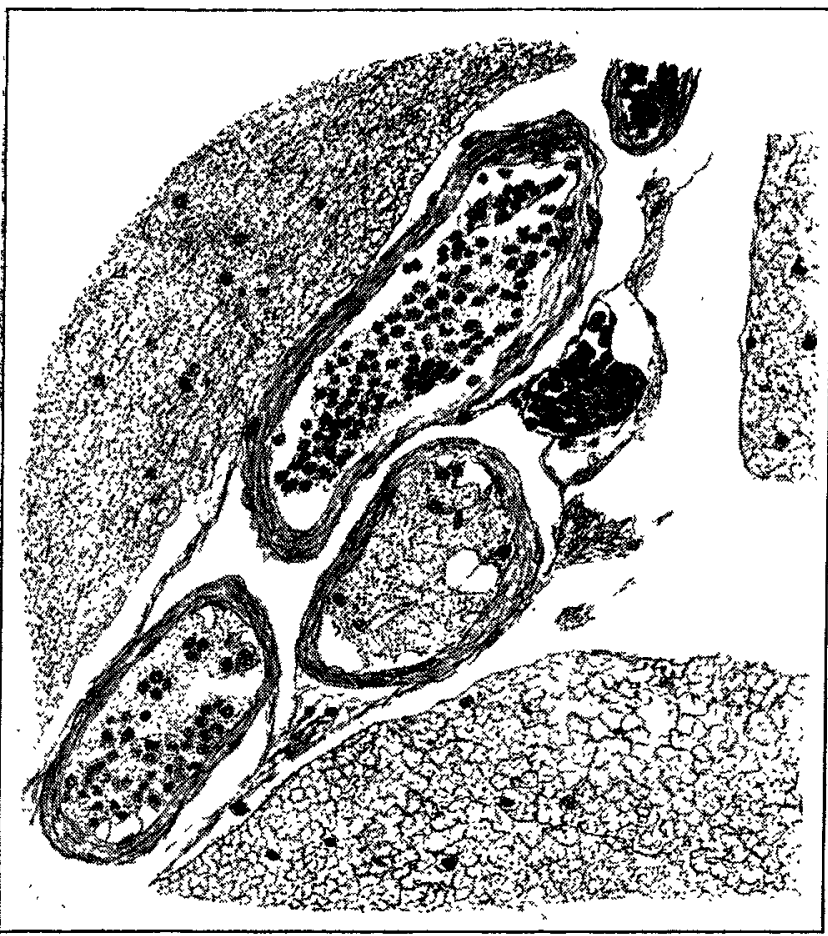

Vessels in calcarine flssure showing leucocytes. $(\times \mathbf{1 5 0 .})$

FIG. 3.

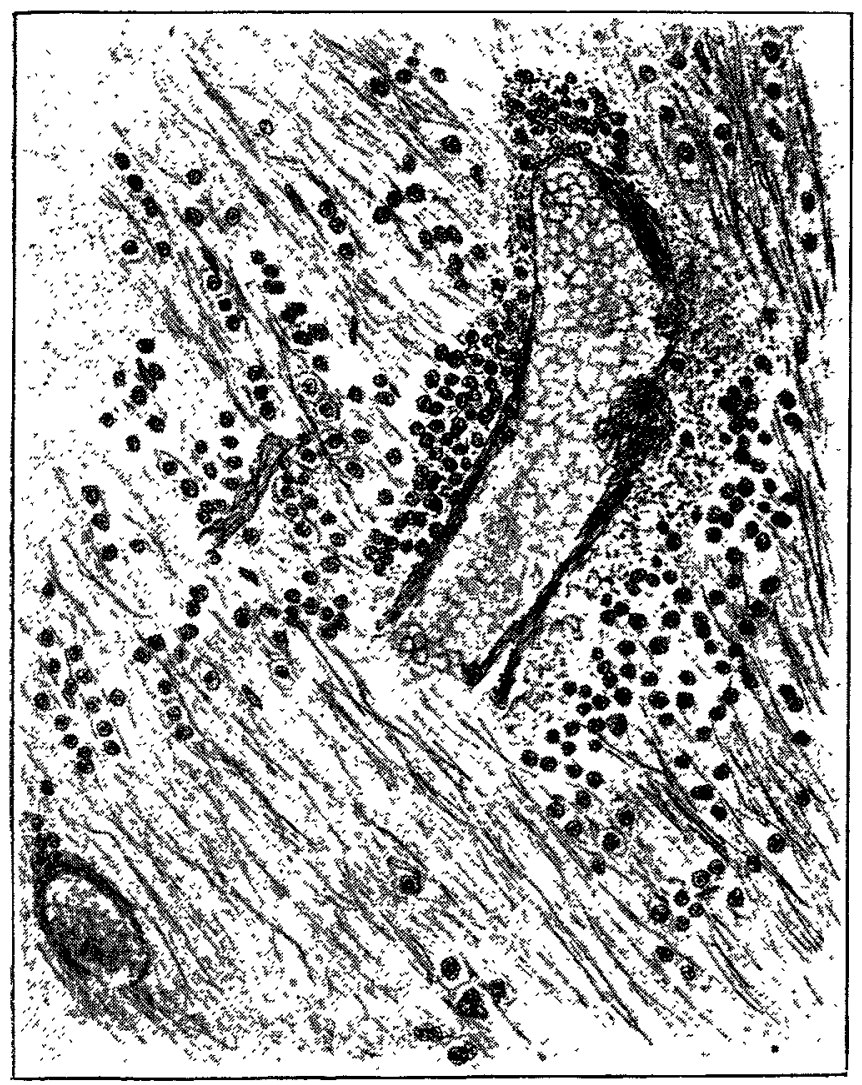

Tegmentum of mid-brain, right side. $(\times 300$.

these cells were very irregular in incidence. For example, in one part of the ascending frontal convolution the Betz cells would be practically normal, whereas in another the majority of the cells were surrounded by small satellite cells or neuronophages. In such areas it was not uncommon to see a nerve cell completely or almost completely broken ${ }^{\circ}$ up, and represented only by a nucleus and a cluster of satellite cells. The same irregular incidence of the nerve cell degeneration was seen in the basal ganglia, in some parts of which a greater proportion of nerve cells appeared to be affected than in any sections of the cortex examined, while in other parts the nerve cells appeared practically normal (Fig. 4).
FIG. 2.

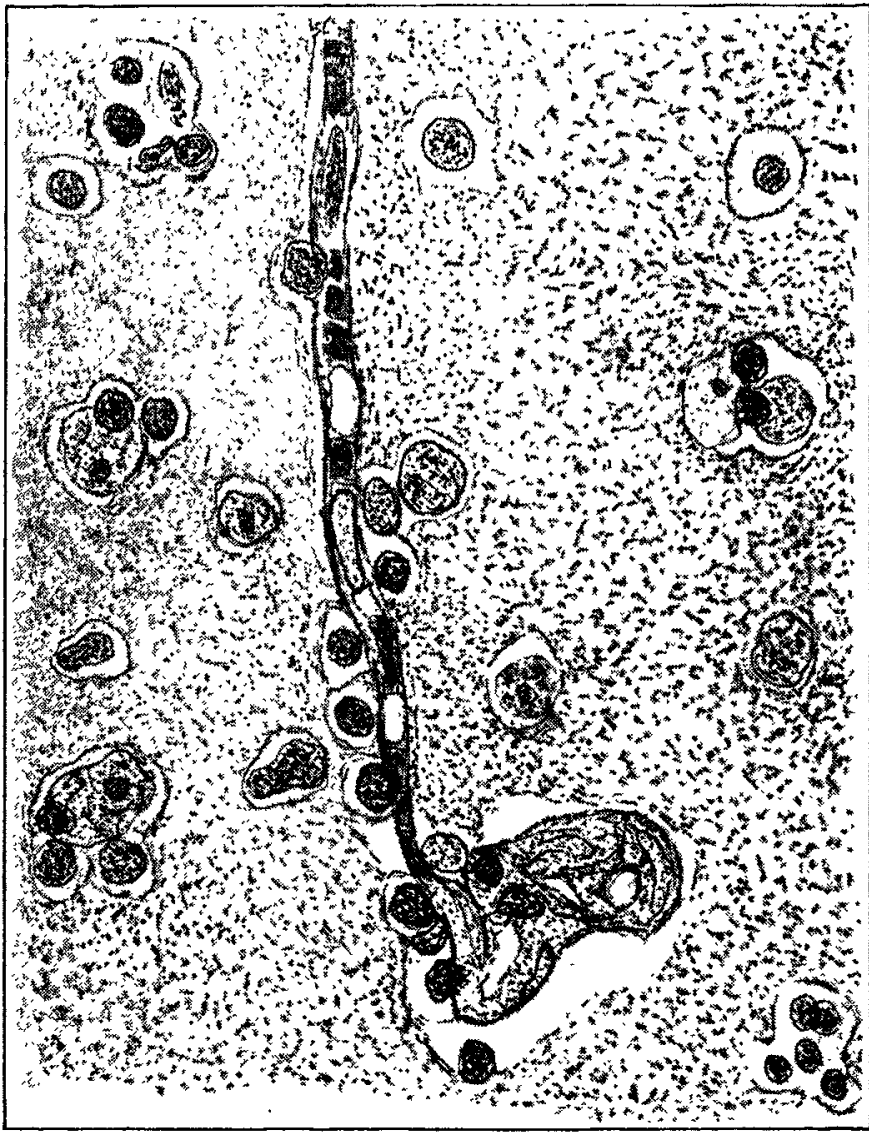

Left caudate nucleus, $(\times 650$.

FIG. 4.

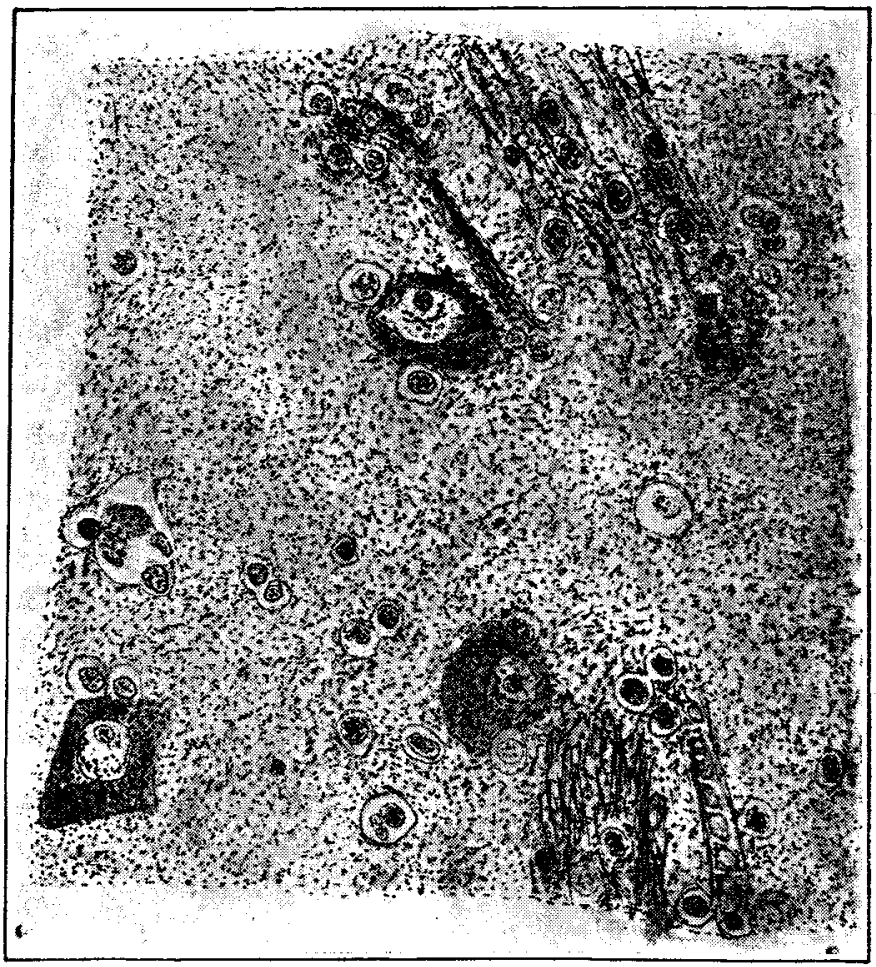

Basal ganglia, right side. $(\times 500$.

In the areas showing the greatest degree of cell degeneration a large number of small degeneration granules, which stained deeply with neutral-red, could be seen both in and around the degenerated nerve cells and in the perivascular sheaths of the vessels. In the brain stem the cells of the superior corpora quadrigemina were slightly degenerated, and a few of the cells of the substantia nigra were surrounded by rings of satellite cells. The cells of the oculo-motor nuclei, the red nucleus, the nuclei pontis, and the nucleus dentatus appeared to be perfectly normal. No micro-organisms could be found in sections stained by Gram's method, either in the meninges, cortex, or basal ganglia. 


\section{Remarks.}

Although this case shows much slighter changes than those described by others it seems to indicate the constancy of the pathological picture in Sydenham's chorea. The macroscopical appearance of the brain was normal except for some subpial hremorrhage in the occipital region. This was thought at first to be an artefact, but the microscopic examination of that part of the cortex showed other changes which must have occurred before death. In many parts of the brain the microscopical changes were of so slight a degree that they might easily have passed unnoticed, but although slight they were quite definite. In other places they were so great that they could scarcely have escaped observation. The sections, in fact, were very similar to those from cases of encephalitis lethargica in the earlier stages of the disease, in which the cellular infiltration of the vessel walls is either absent or is not a prominent feature. The congestion of the vessels, the emergence of small round cells from the walls of the capillaries, and the diffuse neuronophagy resemble very closely the picture of that disease as described by one of us (J.G. G.).

The epidemic of encephalitis lethargica has proved conclusively that a fatal encephalitis may occur without any but the slightest signs of cellular infiltration of the brain tissues. Several of the rapidly fatal cases in the Derby epidemic were completely negative in this respect. It should not surprise us, therefore, that the pathological examination of the brain in cases of acute fatal chorea should so frequently have given no result. In this country pathologists are accustomed to examine organs in small pieces and very thin sections, and unless a very large number of pieces and of sections are examined the changes that are present may pass unnoticed. Marie and Trétiakoff insist on this point, and say that even in their case, where the lesions were evident enough, the examination of small sections might easily have failed to detect them.

In several pathological reports on the brain in cases of chorea we have found no reference to any sections except those of the cortex, and in some only the motor cortex appears to have been examined. In our opinion negative findings by such methods of examination are absolutely valueless. There is now a sufficient body of evidence to prove that the pathological basis of chorea minor is a diffuse or disseminated encephalitis affecting chiefly the corpus striatum and involving the cortex and the pia arachnoid. It seems more than probable that the mioroorganism responsible for this encephalitis is the same as that which causes the carditis and arthritis of rheumatism. The lesions have been most constantly found in the caudate nucleus and the putamen, and in our case they were most evident in these regions. Other authors have found changes of equal degree in the cortex, although there they are apt to be disseminated rather than diffuse, or at least to be much more evident in some areas than others. The incidence of these cortical lesions is very irregular, and as macroscopic sections may give one no help in choosing pieces for microscopical examination it is very easy to miss those which show the greatest changes. This probably accounts for the divergence of opinion as to the importance of the part played by the cortex in the pathological process.

This view of the pathogenesis of chorea takes little account of the presence or absence of embolism of small arteries by fragments of cardiac vegetations. The occurrence of such emboli is disputed by various authors. Whereas Guizzetti and Camisa found them in two cases, they were not found by Poynton and Holmes, nor by Marie and Trétiakoff. In our case their occurrence was doubtful. Although a few of the small arteries both in the meninges and in the substance of the brain were blocked by leucocytic thrombi it was not possible to be certain that these were pieces of cardiac vegetations. The brain tissue in their neighbourhood certainly showed a greater degree of small-celled infiltration than was present elsewhere, but it did not show any evidence of softening, and except in the case of the artery on the occipital surface of the brain there was no sign of such petechial hremorrhages in the neighbourhood as would be caused by the sudden blocking of a vessel. In our opinion it seems more probable that these leucocytic thrombi are formed in situ in the neighbourhood of a concentration of the causative micro-organism. Thrombosis of vessels was frequently observed in our case. and where a fairly large cortical vessel was thrombosed it was common to find that the outer layers of the thrombus contained a very large number of leucocytes. By an exaggeration of such a process a smaller vessel in an infected area would become so plugged with leucocytes that the blood-flow would be arrested.

Whether embolism of small cerebral arteries occurs in chorea or not, it cannot be the cause of the disease. This is shown not only by the diffuse nature of the encephalitis present in many recorded cases but also by certain clinical facts. As was long ago shown by Ogle and by Broadbent many cases of chorea occu in which there is no disease of the cardiac valves. And chorea is never found in cases of ulcerative endocarditis in the adult in which cerebral embolism of greater or less degree is common. Nor do the symptoms of cerebral embolism correspond at all with those of chorea. And it is impossible to imagine that the symptoms produced by a des tructive lesion such as embolism would yield so rapidly to treatment as those of acute chorea frequently do. Again, those who have been the subjects of attacks of chorea in childhood very rarely show any signs of damage or degeneration of the brain in later life. Their intelligence in fact is, as a rule, above the average. On the whole, then, we are entitled to assume that embolism of cerebral arteries, if and when it occurs in Sydenham's chorea, is not the cause of the typical symptoms, but may possibly cause other more lasting effects, such as the hemiparesis which not uncommonly follows the attacks.

It is not possible to be equally dogmatic as to the manner in which this encephalitis gives rise to the clinical symptoms of Sydenham's chorea, but it is interesting to remember (and this point is insisted on by Marie and Trétiakoff) that the lesions in Huntingdon's chorea are also localised in the corpus striatum and the cortex. Recent work by Wilson, the Vogts, and others on the corpus striatum has shown that choreiform movements are frequently associated with disease in this area of the brain.

Finally, we wish to disclaim any originality for our view that chorea is a meningo-encephalitis of rheumatic origin. This view was in essence advanced by Poynton and Holmes, and has been reiterated by several continental authorities. This paper has been put forward merely as one more link in the chain of evidence and in the hope that it may help towards a greater understanding of the essential nature of Sydenham's chorea.

We desire to express our thanks to Dr. Robert Hutchison for his courtesy in allowing us to publish the examination of this case.

References.-1. Todd: THE LANCET, 1843, vol. ii., p. 463 2. Kirkes, W. H.: Medical Times and Gazette, 1863, vol. 1 . 4. Oglo: British and Foreign Medico-Chir., Review, January 245 . Ogle: British and Foreign Medico-Chir. Review, January and April, 1868 . 5. Broadbent, W. H. : Brit. Med. Jour., Jan. 23rd, 7. Maragliano: Centralblatt für Innere Med., Leipzig, 1899, Bd. Xx. S. 449. 8. Wassermann, Westphal, and Malkoff :
Berlin klin. Woch., 1899, S. 628. 9. Dana, C. L. Amer. Jour. of Med. Science, 1894, vol. crii., p. 31. io. Poynton and Paine: Researches on Rheumatism, London, 1913. 11. Beaton and Ainley Walker: Brit. Med. Jour., 1903, vol. i., p. 237 vol. xi., p. 826. 13. Guizzetti and Camisa: Riv. Sper. de vol. xi., p. 826. 13. Guizzetti and Camisa: Riv. Sper. de Freniat. e di Med. Leg., 1911, vol. Xxxvii., p. 266. 14. Harvier and Levaditi : Bull. et Mém. de la Soc. Méd. des Hôp. de Paris, 1920, xliv., t. iii., p. 583, 15. Marie and Trétiakofi: Revue Neurologique, 1920 , t. Xxvii., p. 428, 16. Buzzard and GreenBritish Jour, of Exper. Path., 1921, vol. ii., p. 141 . 